\title{
ANALISIS SIKAP DAN FAKTOR - FAKTOR YANG MEMPENGARUHI KEPUTUSAN KONSUMEN DALAM MENGGUNAKAN ARANG TEMPURUNG KELAPA PADA BEBERAPA USAHA KULINER DI KOTA BANDA ACEH
}

\author{
Analysis Consumer Attitudes And Factors Affecting The Decision Of Consumers In Using \\ Charcoal Coconut Shell On Some Type Of Business To Eat In Banda Aceh
}

\author{
Faridah Hidayati ${ }^{1}$, Rahmaddiansyah $^{1}$, Mustafa Usman ${ }^{{ }^{*}}$ \\ ${ }^{1}$ Program studi Agribisnis, Fakultas Pertanian, Universitas Syiah Kuala
}

\begin{abstract}
Abstrak - Penelitian ini bertujuan untuk mengetahui atribut arang tempurung kelapa yang memiliki skor tertinggi pada keputusan konsumen dalam menggunakan arang tempurung kelapa dan penelitian ini juga bertujuan untuk melihat faktor - faktor apa saja yang memiliki hubungan signifikan dengan keputusan konsumen dalam menggunakan arang tempurung kelapa pada beberapa usaha kuliner di Kota Banda Aceh. Populasi yang digunakan dalam penelitian ini adalah konsumen yang menggunakan arang tempurung kelapa pada usaha kulinernya yaitu pengusaha ikan bakar, ikan tongkol panggang dan mie arang. Sampel pada penelitian ini sebanyak 30 responden dengan metode yang digunakan adalah metode sampling kuota dimana penetuan sampel dari populasi yang memiliki cirri-ciri tertentu sampai jumlah (kuota) yang diinginkan. Metode analisis yang digunakan adalah analisis multiatribut Fishbein dimana metode ini digunakan untuk melihat atribut pada arang tempurung kelapa yang memiliki skor tertinggi pada sikap konsumen dalam menggunakan arang tempurung kelapa pada usaha kulinernya. Sedangkan untuk melihat faktor - faktor yang memiliki hubungan signifikan dengan keputusan konsumen digunakan metode Uji Korelasi Spearman Rank. Berdasarkan hasil analisis bahwa atribut kualitas merupakan atribut yang memiliki skor tertinggi pada keputusan konsumen dalam menggunakan arang tempurung kelapa sedangkan faktor-faktor yang memiliki hubungan dengan keputusan konsumen dalam menggunakan arang tempurung kelapa adalah faktor jenis pekerjaan yang memiliki hubungan positif dan faktor kelompak acuan memiliki hubungan yang negatif dengan keputusan konsumen dalam mengunakan arang tempurung kelapa .
\end{abstract}

Kata kunci : Sikap konsumen, atribut, arang tempurung kelapa

Abstract-This study aims to determine the attributes of coconut shell charcoal that has the highest score on the decisions of consumers in using coconut shell charcoal and this study also aims to look at what factors are having a significant relationship with the consumer's decision to use coconut shell charcoal on several culinary efforts in the city of Banda Aceh. The population used in this study is the consumer who uses coconut shell charcoal in the culinary business, namely employers grilled fish, grilled tuna and noodles charcoal. Samples in this study were 30 respondents to the method used is the method Proportionate Stratified Random Sampling, which is used to determine the number of samples come from populations that have a member or element is not homogeneous and stratified The analytical method used is the analysis of multi-atribut Fishbein where this method is used to view the attributes of the coconut shell charcoal that has the highest score on consumer attitudes in using coconut shell charcoal in the culinary business. As for seeing the factors that have a significant relationship with the consumer's decision to use correlation test methods Spearman Rank. Based on the 
analysis that the quality attributes are attributes that have the highest score on the decisions of consumers in using coconut shell charcoal while the factors that have a relationship with the consumer's decision to use the coconut shell charcoal is a factor in the type of work that has a significant relationship and factor reference group does not have a relationship significantly with the decision of consumers in using coconut shell charcoal.

Keywords: Consumer attitudes, attributes, coconut shell charcoal

\section{PENDAHULUAN}

Kelapa (Cocos nucifera) termasuk jenis tanaman palma yang mempunyai buah berukuran cukup besar. Batang pohon kelapa umumnya berdiri tegak dan tidak bercabang, dan dapat mencapai 10 - 14 meter lebih. Daunnya berpelepah, panjangnya dapat mencapai 3 4 meter lebih dengan sirip - sirip lidi yang menopang tiap helaian. Buahnya terbungkus dengan serabut dan batok yang cukup kuat sehingga untuk memperoleh buah kelapa harus dikuliti terlebih dahulu. Kelapa yang sudah besar dan subur dapat menghasilkan 2 - 10 buah kelapa setiap tangkainya (Palungkun, 2004).

Indonesia merupakan negara agraris yang menempati posisi ketiga setelah Filipina dan India, sebagai penghasil kelapa terbesar di dunia (APCC, 2002). Pemanfaatan buah kelapa umumnya hanya daging buahnya saja untuk dijadikan kopra, minyak dan santan untuk keperluan rumah tangga, sedangkan hasil sampingan lainnya seperti tempurung kelapa belum begitu banyak dimanfaatkan.

Salah satu usaha untuk meningkatkan pendapatan petani kelapa adalah dengan mengolah semua komponen buah menjadi produk yang bernilai tinggi, sehingga nilai buah kelapa akan meningkat. Salah satu produk yang dapat dibuat dari tempurung kelapa adalah pembuatan arang tempurung kelapa yang bisa dimanfaatkan untuk berbagai kebutuhan hidup, salah satunya sebagai bahan bakar alternatif atau bahan bakar pada usaha-usaha kuliner. Tempurungkelapajikadiolah menjadi arang tempurung harganya Rp 2.337 .670 /ton, kalau diolah menjadi arang aktif harganya mencapai $\mathrm{Rp} 9.911 .625$ /ton, ini berarti peningkatan nilai arang tempurung ke arang aktif sebesar Rp 7.574.000/ton (PKAO, 1989).

Suatu produk yang dapat memenuhi kebutuhan dan keinginan dari konsumen tentunya akan terjual dipasaran dengan syarat target pasar produk tersebut tentunya harus memiliki daya beli.Konsumen memutuskan membeli dan mengkonsumsi produk bukan sekedar karena nilai fungsi awalnya, tetapi juga karena nilai sosialnya. Keputusan pembelian merupakan perilaku yang dilakukan oleh individu-individu yang berbeda.Schiffman dan Kanuk (2008) menyatakan bahwa perilaku konsumen menggambarkan cara individu mengambil keputusan untuk memanfaatkan sumber daya mereka yang tersedia (waktu, uang, usaha) guna membeli barang-barang yang berhubungan dengan konsumsi.

Perilaku pembelian konsumen dipengaruhi oleh faktor budaya, sosial, pribadi dan psikologis. Faktor budaya merupakan penentu keinginan dan perilaku konsumen yang paling mendasar. Faktor sosial berasal dari pengaruh kelompok kecil yang terdiri dari dua orang atau lebih yang saling berinteraksi untuk mencapai sasaran tujuan bersama yang dapat mempengaruhi perilaku seseorang. Faktor sosial meliputi keluarga, serta peran dan status sosial seseorang. Faktor pribadi meliputi usia, pekerjaan, keadaan ekonomi, gaya hidup, dan

Analisis Sikap Konsumen Dan Faktor - Faktor Yang Mempengaruhi Keputusan Konsumen Dalam 208 Menggunakan Arang Tempurung Kelapa Pada Beberapa Jenis Usaha Kuliner Di Kota Banda Aceh (FaridahHidayati, Rahmaddiyansyah ,Mustafa Usman,)

Jurnal Ilmiah Mahasiswa Pertanian Unsyiah, Vol. 2, No. 2, Mei 2017: 207-213 
kepribadian seseorang. Faktor psikologis yang mempengaruhi keputusan seseorang dalam membeli produk adalah motivasi, persepsi, keyakinan, sikap dan pembelajaran.

Adapun tujuan dari penelitian ini adalah untuk mengetahui atribut arang tempurung kelapa yang memiliki skor tertinggi dan faktor-faktor apa saja yang mempengaruhi keputusan konsumen dalam menggunakan arang tempurung kelapa pada beberapa usaha kuliner di Kota Banda Aceh.

\section{METODE PENELITIAN}

Metode yang digunakan dalam penelitian ini adalah metode Proportionate Stratified Random Sampling, dimana digunakan untuk menentukan jumlah sampel yang berasal dari populasi yang mempunyai anggota atau unsur yang tidak homogen dan berstrata. Jenis data yang dikumpulkan dalam penelitian ini adalah data primer dan data sekunder. Data primer diperoleh dari observasi langsung menggunakan panduan wawancara yang telah dipersiapkan terlebih dahulu sesuai dengan tujuan penelitian. Data sekunder diperoleh dari instansi-instansi yang terkait dengan penelitian baik dari instasi pemerintah, swasta maupun perpustakaan.

Berdasarkan hipotesis yang telah diuraikan, maka metode analisis yang digunakan adalah metode multi atribut Fishbein, yaituyang digunakan untuk mengetahui bagaimana sikap konsumen terhadap arang tempurung kelapa. Model Fiesbein menyatakan bahwa perilaku konsumen akan ditentukan oleh sikap terhadap berbagai atribut yang dimiliki oleh arang tempurung kelapa. Sedangkan untuk mengetahui faktor - faktor yang mempengaruhi keputusan konsumen dalam menggunakan arang tempurug kelapa digunakan metode analisis Spearman Rank.

Metode analisis dan pengujian hipotesis yang digunakan dalam penelitian ini, yaitu :

\section{a. Analisis Multiatribut Fishbein}

Model ini digambarkan sebagai berikut (Sumarwan, 2004):

$$
\text { Ao }=\sum_{i=1}^{n} \text { biei }
$$

Dimana :

$\mathrm{Ao}=$ Keseluruhan sikap terhadap suatu objek

bi= Kepercayaan seseorang terhadap atribut (i) yang ada pada suatu objek

ei $=$ Penilaian (evaluasi) seseorang terhadap atribut (i) yang ada pada suatu objek

$\mathrm{n} \quad=$ Jumlah atribut yang dimiliki objek

\section{b. Spearman Rank}

Metode korelasi Spearman rank adalah metode yang bekerja untuk skala data ordinal atau rangking dan bebas distribusi.Koefisien korelasi ialah pengukuran statistik kovarian atau asosiasi antara dua variabel. Besarnya koefisien korelasi berkisar antara +1 sampai dengan -1 . Koefisien korelasi menunukkan kekuatan (strength) hubungan linear dan arah hubungan dua variabel acak. 
Tabel 1 . Makna Nilai Korelasi Spearman Rank

\begin{tabular}{|c|c|}
\hline Interval Koefisien & Makna \\
\hline 0 & Tidak ada korelasi \\
\hline $0-0,25$ & Korelasi sangat lemah \\
\hline $0,25-0,5$ & Korelasi cukup \\
\hline $0,5-0,75$ & Korelasi kuat \\
\hline $0,75-0,99$ & Korelasi sangat Kuat \\
\hline 1 & Korelasi sempurna \\
\hline
\end{tabular}

Sumber : Sarwono, 2006

Pada koefisien kepercayaan 95\% dantaraf nyata 0,05 maka kriteria penarikan kesimpulan.

Hipotesis :

Ho : Tidak memiliki hubungan signifikan antara kedua variabel

Ha : Memiliki hubungan signifikan antara kedua variabel

Dengan ketentuan :

- Jika angka signifikansi $<0,05$, maka hubungan kedua variabel signifikan

- Jika angka signifikan >0,05, maka hubungan kedua variabel tidak signifikan

\section{Keputusan Konsumen}

\section{HASIL DAN PEMBAHASAN}

Keputusan pembelian merupakan keputusan dalam menentukan pilihan yang dilakukan oleh konsumen pada arang tempurung kelapa yang dalam penelitian ini merupakan konsumen yang sudah menggunakan arang tempurung kelapa di Kota Banda Aceh yang tersebar pada tiga jenis usaha kuliner yaitu ikan bakar, ikan tongkol panggang dan mie arang.

Tabel 2. Alasan konsumen Dalam Memilih Arang Tempurung Kelapa Pada Beberapa Usaha Kuliner di Kota Banda Aceh.

\begin{tabular}{|l|l|l|l|l|l|l|l|l|l|l|l|l|l|l|}
\hline No & Keputusan & \multicolumn{2}{|c|}{ STS } & \multicolumn{2}{|c|}{ TS } & \multicolumn{3}{c|}{ N } & \multicolumn{2}{|c|}{ S } & \multicolumn{3}{c|}{ SS } & \multicolumn{2}{c|}{ Total } \\
\cline { 2 - 15 } & Konsumen & Fr & $\%$ & Fr & $\%$ & Fr & $\%$ & Fr & $\%$ & Fr & $\%$ & Fr & $\%$ \\
\hline 1. & $\begin{array}{l}\text { Jenis } \\
\text { pekerjaan }\end{array}$ & 0 & 0,0 & 0 & 0,0 & 1 & 3 & 13 & 43 & 16 & 54 & 30 & 100 \\
\hline 2. & $\begin{array}{l}\text { Kelompok } \\
\text { acuan }\end{array}$ & 2 & 7 & 25 & 83 & 0 & 0,0 & 3 & 10 & 0 & 0,0 & 30 & 100 \\
\hline
\end{tabular}

Sumber: Data primer (diolah), 2016.

Keterangan :

STS : Sangat Tidak Setuju

TS : Tidak Setuju

$\mathrm{N} \quad$ : Netral

S : Setuju

SS : Sangat Setuju

Analisis Sikap Konsumen Dan Faktor - Faktor Yang Mempengaruhi Keputusan Konsumen Dalam

210 Menggunakan Arang Tempurung Kelapa Pada Beberapa Jenis Usaha Kuliner Di Kota Banda Aceh (FaridahHidayati, Rahmaddiyansyah ,Mustafa Usman,)

Jurnal Ilmiah Mahasiswa Pertanian Unsyiah, Vol. 2, No. 2, Mei 2017: 207-213 
Tabel 2. menunjukan bahwa alasan konsumen dalam memilih arang tempurung kelapa pada beberapa usaha kuliner di Kota Banda Aceh yang dominan menjadi alasan konsumen adalah faktor jenis pekerjaan yang menyatakan sangat setuju sebesar 54\%, hal ini dikarenakan oleh jenis pekerjaan konsumen yang mendukung konsumen untuk menggunakan arang tempurung kelapa. Sedangkan pada variabel kelompok acuan sebesar 83\% menyatakan tidak setuju, karena konsumen memilih menggunakan arang tempurung kelapa tidak dipengaruhi oleh rekan atau keluarga.

\section{Analisis Multiatribut Fishbein}

Model multiatribut Fishbein menyatakan bahwa sikap seorang konsumen terhadap suatu objek/produk akan ditentukan oleh sikap konsumen tersebut terhadap atribut-atribut yang ada pada objek/produk tersebut.

Tabel 3. Keputusan Konsumen pada Arang Tempurung Kelapa di Kota Banda Aceh

\begin{tabular}{|c|c|c|c|}
\hline No. & Atribut & Kepercayaan & Evaluasi \\
\hline 1. & Harga & 4,3 & 4,4 \\
\hline 2. & Kualitas & 4,7 & 4,9 \\
\hline 3. & Kemasan & 3,9 & 3,7 \\
\hline
\end{tabular}

Sumber: Data primer (diolah), 2016

Berdasarkan Tabel 3. menunjukan pada atribut harga nilai skor pada evaluasi lebih tinggi dibandingkan dengan skor pada kepercayaan. Hal ini disebabkan oleh harga arang tempurung kelapa yang berkisar antara Rp 3.000, - Rp 4.000 per-karung yang dianggap masih tergolong murah bagi responden, sehingga memudahkan responden dalam hal pembelian. Begitu juga pada atribut kualitas yang skor tertingi berada pada evaluasi dari pada kepercayaan dengan nilai skor 4,9. Ini menunjukan kualitas arang tempurung kelapa memiliki tingkat kepentingan yang lebih tinggi bagi responden. Sedangkan pada atribut kemasan nilai skor tertinggi berada pada kepercayaan dengan nilai skor 3,9, hal ini menunjukan bahwa atribut kemasan arang tempurung kelapa bukan merupakan atribut yang penting bagi konsumen dalam menggunakan arang tempurung kelapa.

Tabel 4. Data Hasil Rata - Rata Analisis Model Multiatribut Fishbein

\begin{tabular}{|c|c|c|c|c|}
\hline \multicolumn{2}{|c|}{ Keputusan Konsumen (Ao = bi x ei ) } & \multirow{2}{*}{ Skor Sikap } & \multirow{2}{*}{ Interpretasi sikap } \\
\hline Harga & Kualitas & Kemasan & & Positif \\
\hline 20.2 & 22.2 & 12.3 & 57.0 & \\
\hline
\end{tabular}

Sumber : data primer (diolah), 2016

Berdasarkan Tabel 4. dapat dilihat hasil rata - rata pengukuran sikap terhadap 30 responden yang diteliti. Dimana total skor nilai yang diperoleh sebesar 57.0,termasuk kategori sikap yang positif yang bermakna responden setuju menggunakan arang tempurung kelapa. Rerata nilai sikap masing-masing atribut memperlihatkan kisaran dari 12,3 (kemasan) sampai dengan 22,2 (kualitas), yang berarti bahwa sikap paling positif yang diberikan oleh konsumen adalah pada atribut kualitas, dan sikap yang paling rendah adalah pada atribut kemasan. 
Dari uraian diatas dapat disimpulkan bahwa atribut arang tempurung kelapa yang memiliki skor tertinggi pada keputusan konsumen dalam menggunakan arang tempurung kelapa adalah atribut kualitas.

\section{Faktor - Faktor yang Mempengaruhi Keputusan Konsumen dalam Menggunakan \\ Arang Tempurung Kelapa pada Usaha Kuliner}

Untuk melihat secara keseluruhan apakah faktor jenis pekerjaan dan kelompok acuan memiliki hubungan signifikan terhadap keputusan konsumen dilakukan pengujian dengan menggunakan korelasi Spearman's Rank pada taraf 5\% (0,05).

Tabel 5. Hubungan Jenis Pekerjaan dengan Keputusan Konsumen dalam Menggunakan Arang Tempurung Kelapa Di Kota Banda Aceh

Correlations

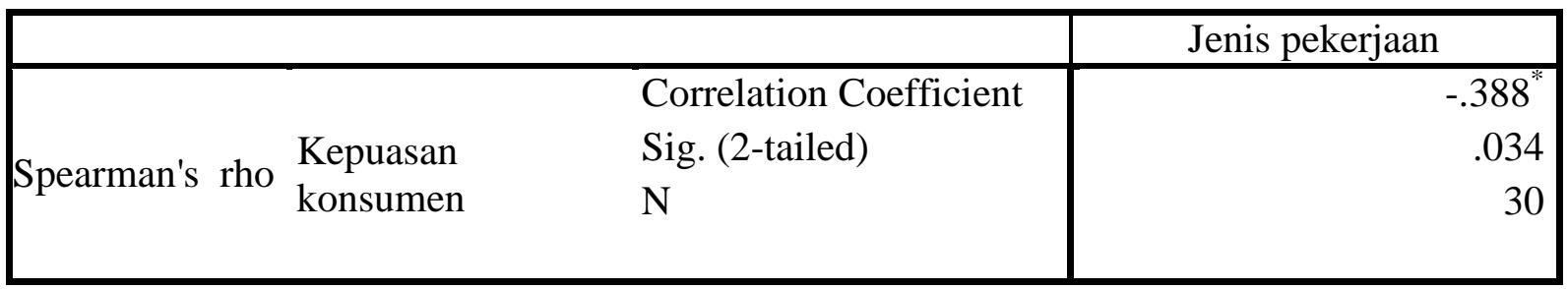

Sumber : data diolah (2016)

Berdasarkan Tabel 5 terlihat angka koefisien korelasi Spearman sebesar 0,388, artinya besar korelasi antara keputusan konsumen dengan jenis pekerjaan ialah sebesar 0,388 atau cukup kuat. Karena angka koefisien korelasi hasilnya negatif yaitu $-0,388$ maka korelasi kedua variabel tidak searah, maksudnya jika kategori jenis pekerjaantinggi maka kategori keputusan konsumen menurun. Didasarkan pada kriteria hubungan kedua variabel dimana angka signifikan sebesar $0,034<0,05$, artinya terdapat hubungan yang signifikan antara keputusan konsumen dengan jeniss pekerjaan. Dari uraian tersebut dapat disimpulkan bahwa korelasi antara variabel keputusan konsumen dan jenis pekerjaan cukup kuat, signifikan dan tidak searah.

Tabel 6. Hubungan Kelompok Acuan dengan Keputusan Konsumen dalam Menggunakan Arang Tempurung Kelapa Di Kota Banda Aceh

Correlations

\begin{tabular}{|lll|r|}
\hline & & \multicolumn{2}{|c|}{ Kelompok acuan } \\
\hline \multirow{2}{*}{$\begin{array}{l}\text { Spearman's } \\
\text { rho }\end{array}$} & Kepuasankonsume & Correlation Coefficient & .137 \\
& $\mathrm{n}$ & $\mathrm{N}$ & .471 \\
& & & 30 \\
\hline
\end{tabular}

Sumber : data diolah (2016)

Berdasarkan tabel 6. terlihat angka koefisien korelasi Spearman sebesar 0,137, artinya besar korelasi antara keputusan konsumen dengan kelompok acuan ialah sebesar 0,137 atau sangat lemah. Karena angka koefisien korelasi hasilnya positif yaitu 0,137 maka korelasi

Analisis Sikap Konsumen Dan Faktor - Faktor Yang Mempengaruhi Keputusan Konsumen Dalam 212 Menggunakan Arang Tempurung Kelapa Pada Beberapa Jenis Usaha Kuliner Di Kota Banda Aceh (FaridahHidayati, Rahmaddiyansyah ,Mustafa Usman,)

Jurnal Ilmiah Mahasiswa Pertanian Unsyiah, Vol. 2, No. 2, Mei 2017: 207-213 
kedua varibael searah, maksudnya jika kategori kelompok acuan tinggi maka kategori keputusan konsumen juga akan naik. Didasarkan pada kriteria hubungan kedua variabel dimana angka signifikan sebesar 0,471>0,05, artinya tidak terdapat hubungan yang signifikan antara keputusan konsumen dengan kelompok acuan. Dari uraian tersebut dapat disimpulkan bahwa korelasi antara variabel keputusan konsumen dan kelompok acuan tidak signifikan.

\section{KESIMPULAN DAN SARAN}

Berdasarkan hasil analisis Fishbein, responden menyatakan bahwa kualitas arang tempurung kelapa menjadi alasan keputusan responden dalam menggunakan arang tempurung kelapa. Dari hasil uji korelasi Spearman Rankdidapatkan bahwa faktor jenis pekerjaan memiliki hubungan signifikan terhadap keputusan konsumen dimana kekuatan korelasi cukup kuat dengan nilai sebesar - 0,388, dengan nilai signfikansi $0,034<0,05$. Sedangkan faktor kelompok acuan memiliki nilai korelasi sebesar 0,137 artinya kekuatan korelasi sangat lemah dan nilai signifikansi sebesar $0,471>0,05$.

Bagi pengusaha arang tempurung kelapa untuk terus meningkatan kualitas pelayanan terhadap konsumen terutama dari segi kemasan yang lebih bagus dari yang sebelumnya masih ada yang menggunakan karung tidak bagus dan juga mengembangkan kreatifitas terhadap produk arang tempurung kelapa sesuai dengan keinginan konsumen.

\section{DAFTAR PUSTAKA}

APPC, 2002. Coconut statistical yearbook 2000. Asia Pacipic Coconut Community. Thailand

Kotler, Philip, 2008. Manajemen Pemasaran. Edisi Milenium diterjemahkan Benyamin Molan, PT. Prenhallindo : Jakarta

Maya, kartika S. 2011. Potensi dan Peluang Kelayakan Ekspor Arang Tempurung Kelapa di Kabupaten Banyumas. Jurnal Pertanian. Bogor

Palungkun, R. 2004. Aneka Produk Olahan Kelapa.Cetakan ke Sembilan. Penebar Swadaya: Jakarta

PKAO. 1989. Basic Data. Pilipinas Kao Inc

Schiffman and Lazar Kanuk. 2008. Perilaku Konsumen. PT Indeks Gramedia. Jakarta

Sumarwan, U. 2004. PerilakuKonsumen: TeoridanPenerapannyadalamPemasaran. GhaliaIndonesia :Bogor

Sunyoto, Danang. 2013. Perilaku Konsumen. CAPS (Center of Academy Publishing Service), Yogyakarta 